W.P. 07-08

Mergers and collusion with asymmetric capacities

Emilie Dargaud

Mars 2007

GATE Groupe d'Analyse et de Théorie Économique

UMR 5824 du CNRS

93 chemin des Mouilles - 69130 Écully - France

B.P. $167-69131$ Écully Cedex

Tél. +33 (0)4 72866060 - Fax +33 (0)4 72866090

Messagerie électronique gate@gate.cnrs.fr

Serveur Web : www.gate.cnrs.fr 


\title{
Mergers and collusion with asymmetric capacities *
}

\author{
DARGAUD Emilie ${ }^{\dagger}$ \\ GATE $^{\ddagger}$ \\ University Lyon 2
}

Abstract. When it examines the risk of coordinated effects, an antitrust authority will usually compare the situation where the merger is accepted with an attendant risk of collusion with the benchmark case in which competition is present ex-post. The main objective of this paper is to show that the antitrust authority must take into account the possibility for firms to collude if a merger is rejected. In fact, firms can have incitations to make collusion ex-post (after a rejection of a merger) whereas they would not make collusion ex-ante. All the papers on mergers and collusion tend to look at a minimal discount factor threshold for collusion to be sustained. This article does not only suggest necessary and sufficient conditions for collusion to be enforced but it also analyses the choice which firms have as to whether to collude. We consider an industry with cost-asymmetric firms and we study the analysis of collusion under leniency programmes.

Keywords: Mergers; Collusion; Leniency programmes

JEL classification: L11, L41, K42

\footnotetext{
*I am particularly grateful to Patrick Sylvestre-Baron for his very helpful comments. I benefited from discussions with and comments from Laurent Flochel and Bruno Versaevel. I would like to thank Ashley Roughton and David Balan for their valuable comments. Of course any errors remain my own.

${ }^{\dagger}$ Tel.: +33(0)472866112 ; fax: +33(0)472866090 ; e-mail: dargaud@gate.cnrs.fr

${ }^{\ddagger}$ Groupe d'Analyse et de Théorie Economique, UMR 5824 du CNRS -93, chemin des mouilles, 69130 Ecully- France
} 


\section{Introduction}

Collusion enables firms to exert market power they would not otherwise have, restricts competition and increases prices. Combatting collusion is a major area of activity for any antitrust authority. In particular, this point is addressed in merger cases. Ex ante, competition authorities can prevent the emergence of an industry structure that is prone to collusion, by taking into account this concern when examining proposed mergers. They can also ban facilitating practices. Ex post, competition authorities can take steps to fight collusion per se, e.g., by uncovering evidence of explicit coordination or by attacking specific agreements that again facilitate collusion.

Economic theory suggests that a merger might engender the creation of collusive outcomes because the merger reduces the number of firms and also gives rise to a more symmetric distribution of assets.

Compte et al. (2002), inspired by the Nestlé-Perrier merger case ${ }^{1}$, showed that the introduction of asymmetric capacities makes collusion more difficult to sustain when aggregate capacity is limited. Giving larger shares of the collusive profits to the bigger firms alleviates somewhat the tension generated by asymmetric capacities, but it does not eliminate it entirely, and the scope for collusion is nonetheless reduced.

Rothschild (1999) and Vasconcelos (2005) both dealt with collusion under cost asymmetry when firms compete à la Cournot. Rothschild used standard grim trigger strategies. Vasconcelos looked for more general punishments with a stick-and-carrot structure as proposed by Abreu (1986, 1988) and analysed tacit collusion in quantity-supergames involving costasymmetric firms and showed that if a merger brings about an increase in the inequality of asset holdings then collusion will be inhibited.

All proposed mergers notified to the antitrust authority are examined to see if they would significantly impede effective competition. The antitrust

\footnotetext{
${ }^{1}$ European Commission, Case Number IV/M 190: Nestle and Perrier, 92/553/EEC
} 
authority analyses if the proposed merger can make more likely or more effective for firms to coordinate their actions (coordinated effects) and if it can make profitable for the merging firms to reduce output and raise price unilaterally (unilateral effects) ${ }^{2}$.

When it examines the risk of coordinated effects, an antitrust authority will usually compare the situation where the merger is accepted with an attendant risk of collusion with the benchmark case in which competition is present ex-post. But the latter is a strong assumption since it considers that firms automatically act competitively after a rejection of a project of merger. The antitrust authority does not take into account the possible collusion after a rejection of a merger.

The main objective of this paper is to show that the antitrust authority must take into account the possibility for firms to collude if a merger is rejected. In fact, firms can have incitations to make collusion ex-post (after a rejection of a merger) whereas they would not make collusion ex-ante (before a project of merger).

We analyse how asymmetry in cost function across firms, as was suggested by Perry-Porter (1985), can affect the scope of collusion after a merger. Perry and Porter (1985) but also Farrell and Shapiro (1990) challenged the view that a merged firm is no larger than any of the constituent firms (as in the model of Salant, Switzer and Reynolds in 1983). These studies introduce the existence of some crucial assets that are in limited supply in order to capture the notion that some firms are larger than others in a homogeneous product industry. This assumption implies rising marginal cost of output production and, consequently, internal cost savings from mergers could make a merger profitable.

In this setting we show that a merger, under certain conditions, can create a market structure which decreases the possibility of collusion. In

\footnotetext{
${ }^{2}$ Council Regulation (EC) no 139/2004
} 
particular, when two firms with high production capacities merge, then the space of parameters for which firms collude decreases after this merger.

All the papers on mergers and collusion tend to look at a minimal discount factor threshold for collusion to be sustained. There is one main difference between these papers and ours : this article does not only suggest necessary and sufficient conditions for collusion to be enforced but we do analyse the choice which firms have as to whether to collude. We look at the equilibrium path of firms. The analysis indicates whether collusion is taking place or not in reality.

Another strand of literature related to this paper deals with leniency programmes (as Motta-Polo, 2003)(henceforth LP). These programmes reduce fines for cartel members who report themselves to and assist the antitrust authority, and the impact of LP can be seen in the recent increase in successful cartel investigations. For example, in the period from 14 February 2002 to the end of 2005, the European Commission received 167 applications under the 2002 Leniency Notice. Of these applications, 87 were requests for immunity and 80 were requests for reduction in fines. The Commission has granted 51 decisions for conditional immunity. Over the same period, the Commission rejected or decided not to deal any further with 23 applications and had under scrutiny 13 more recent applications. ${ }^{3}$

The presence of LP introduces a coordination game between the cartel members (apply for leniency or not?). As in Motta-Polo (2003), LP have two possible effects. The first is the deviation from the cartel agreement by firms which report to the antitrust authority. The second (being a negative effect) is the attenuation of the expected cost of anticompetitive behaviour because of reduced fines. The key mechanism of LP is the rule that allows firms to receive fine reductions even after an investigation is opened.

Motta-Polo (2003) showed that if the antitrust authority has limited

\footnotetext{
${ }^{3}$ European Commission, MEMO/06/357.
} 
resources, then the scope of collusion can be decreased by using LP. The main difference between the paper of Motta and Polo and ours is that here there is a possibility for some firms to merge. Moreover, we consider asymmetric firms.

The article is organized as follows. In section 2 we describe the basic model. Characterizations of equilibria and implications for merger control are provided in section 3. Concluding remarks follow in section 4. Proofs of results and graphics appear in the appendix.

\section{The model}

Consider an industry with $n$ asymmetric firms. By asymmetry it is meant that firms have a different share of a specific asset that affects marginal costs. More precisely, in the model, two identical firms have the same production capacity, denoted by $k_{1}=k_{2}$. The other firms have the same fraction of the industry capital stock $k_{j}(\forall j \in n, j \neq 1,2)$. This asymmetry is introduced in each firm's cost function. A firm is deemed large for the purposes of the model if it owns a large fraction of the capital stock.

Following Perry and Porter (1985), cost is assumed depend on the capital owned by the firms : $C\left(q_{i}, k_{i}\right)=\frac{q_{i}^{2}}{2 k_{i}}+q_{i} c, \forall i \in[1, n]$ where $q_{i}$ denotes the quantity chosen by firm $i, \forall i \in[1, n]$. Fixed costs are zero.

Cost asymmetry is conventionnally seen as hindering collusion because low-cost firms are more difficult to discipline, both because they might gain more from undercutting their rivals and because they have less to fear from possible retaliation from high-cost firms.

Firms compete on a Cournot basis with a homogeneous product. We assume that the demand function is linear i.e., $p=1-Q$.

Firms can make collusive agreements after firms 1 and 2 have proposed a merger which has either been accepted or rejected by the competition authority in the first period. The outcome of the execution of a collusive 
agreement is assumed to be that the colluding firms will thence reduce output below the competitive level. Quantity competition also affects retaliation possibilities as well as the short-run gains of deviations from collusive conduct. Indeed, under quantity competition, one is less tempted to increase production levels in order to deviate from a tacitly collusive level, since prices will adjust to enable the competitors to sell all their output.

This would tend to make collusion easier to sustain. However, retaliation is somewhat harder under quantity competition because the firm that is the object of retaliation can always soften the blow (compared to a situation of price competition) by changing its output level accordingly.

We extend the framework of Motta-Polo (2003) by introducing a first stage in which the antitrust authority decides to accept or reject a notification of merger between two firms. The antitrust authority (henceforth : AA) uses leniency programmes; these programmes provide the incentive of reduced fines to firms which reveal information about collusion to the AA.

Four exogenous parameters summarize the enforcement policy:

- $F \in[0, \bar{F}]:$ the value of the fine if firms are detected by the AA and have not cooperated with it, $\bar{F}$ being the maximum possible fine which can be imposed.

- $f \in[0, F]$ : the value of the reduced fine for the firm which denounces the collusive agreement. It is assumed that all firms which cooperate with the AA will be granted reduced fines. It is also assumed that the reduction is high enough in order for the LP be really effective because if $f$ is close to the full fine, $F$ there is no incentive to reveal.

- $\alpha \in[0,1]$ : the probability that firm is reviewed by the AA.

- $s \in[0,1]$ : the probability that the AA successfully concludes the investigation when firms do not cooperate. 
Type I errors (firms not colluding are still prosecuted) are assumed not to happen and Type II errors (colluding firms not fined) are assumed to happen.

The collusion strategy is modelled on the basis of a trigger strategy: once a firm deviates from the collusive agreement, all the firms will play non cooperatively until the end of the game. These strategies have been initially suggested by Friedman (1971).

The timing of the game is as follows:

The game starts $(t=0)$ with the AA approving or rejecting the notification of the merger between two firms, 1 and 2 .

After this first stage, the game is repeated indefinitely. It can be formally described as follows.

At $t=1$, firms decide to reach a collusive agreement or to deviate (playing non cooperatively). If no firm deviates until a time $t$ then they collude again and get a profit $\pi_{M}$. We study the case in which firms can sustain the joint profit maximisation, so the subscript $M$ indicates a collusive outcome since collusion aims at monopolizing the industry. If at time $t$ the AA decides to open an investigation then there are two assumed outcomes :

- Cooperation: firms denounce the cartel to the AA; they pay the reduced fine $f$ and play non cooperatively during one period and restart collusion after an inquiry is concluded. If however a firm deviates from the collusive agreement, firms play non cooperatively until the end of the game.

- No cooperation: the investigation begins at $t+1$. If firms are not condemned, which occurs with probability $(1-s)$, then they continue to play cooperatively; if they are found guilty, then they pay the total fine $F$ and they have to play non cooperatively during one period. As in the cooperation case, if one firm deviates from the collusive agreement, firms play non cooperatively until the end of the game. 
Consequently, there are two types of deviation in this game: the deviation from the collusive agreement and the reporting to the AA.

The equilibrium of the game can now be analysed.

\section{$3 \quad$ Equilibria}

This section describes the various types of equilibria. We describe the perfect Nash equilibria of the game and we have to resolve this game considering merger or not in the first period.

Motta and Polo (2003) suggested that there are three types of equilibria: no collusion $(\mathrm{NC})$, collusion and revelation $(\mathrm{CR})$ and collusion and no revelation (CNR). The existence of these equilibria depends on the value of the relevant parameters.

CR equilibrium exists if the profit of firm colluding and revealing to the $\mathrm{AA}$ is greater than the profit of a firm which deviates.

CNR equilibrium exists if firm which colludes and does not reveal information has no incentive to reveal information to the AA and also to deviate from the collusive agreement.

Let $\delta \in(0,1)$ be the common discount factor.

The results obtained by Motta-Polo (2003) are as follows:

lemma 1. (Motta-Polo (2003) for low values of $f$ )

- for $s \in\left[0, s_{C N R}\right)$ and $\alpha \in\left[0, \min \left(1, \alpha_{N C}(s)\right): C N R\right.$ exists.

- for $s \in\left[s_{N C}, 1\right]$ and $\alpha \in\left[\max \left(\alpha_{N C}(s), \alpha_{C R}\right), 1\right]: N C$ exists.

- for $s \in\left[s_{C N R}, 1\right]$ and $\alpha \in\left[0, \alpha_{C R}\right): C R$ exists. 
with:

$$
\left\{\begin{aligned}
s_{N C} & =\frac{(1+\delta)\left(\pi_{M}-(1-\delta) \pi_{D}-\delta \pi_{N}\right)}{\delta^{2}\left(\pi_{M}-\pi_{N}+F\right)} \\
s_{C N R} & =\frac{(1+\delta)\left(\pi_{M}-\pi_{N}+f\right)}{\delta\left(\pi_{M}-\pi_{N}+F\right)} \\
\alpha_{C R} & =\frac{\pi_{M}-(1-\delta) \pi_{D}-\delta \pi_{N}}{\left(\pi_{M}-\pi_{N}+f\right)} \\
\alpha_{N C} & =\frac{(1+\delta)\left(\pi_{M}-(1-\delta) \pi_{D}-\delta \pi_{N}\right)}{\delta s\left(\pi_{M}-\pi_{N}+F\right)}
\end{aligned}\right.
$$

[Insert figure 1]

Figure 1 in the appendix represents graphically the Subgame Perfect Equilibria.

The region labelled 1 in the figure 1 represents the area where parameters lead to CR under leniency programs with no actual leniency. Region 2 represents the area where the parameters are such as to make ex-post desistence more easy by encouraging revelation and by shortening investigation time.

Note that $\alpha_{C R} \geq 0$ for $\delta>\tilde{\delta}=\frac{\pi_{D}-\pi_{M}}{\pi_{D}-\pi_{N}}$ which is the usual critical discount factor when firms collude with no threat of prosecution.

\subsection{The impact of a merger on collusion}

In this subsection, the first stage of the game is examined in more detail. Two cases must be analysed depending on whether the merger is accepted in the first period or not. If the AA rejects the merger in the first period, then the repeated game is played with $n$ firms. As said before, the two firms which are proposing to merge are identical $\left(k_{1}=k_{2}\right)$. The others have the same production capacity : $k_{i}=k_{j}, \forall i \in n, i \neq(1,2) ; \sum_{i=1}^{n} k_{i}=1$.

Received wisdom suggests that mergers may tend to create structural conditions which facilitate collusion. Firstly, coordination is easier to sustain when the number of competitors is smaller and secondly, as the number of firms decreases, each firm gets a higher share of the market. This has two implications, the gain from deviating decreases for each firm and the longterm benefit of maintaining collusion is increased because it gets a higher share of the collusive profit. 
The impact of a merger on collusion is captured in our framework by the comparative static on $\alpha_{C R}, \alpha_{N C}$ and $s_{C N R}$.

We are going to detail the proceeding of the comparative static on $\alpha_{C R}$ and it will be the same conduct for the others.

To do this, we compute the value of $\phi=\frac{\alpha_{C R}^{b m}}{\alpha_{C R}^{\alpha m}}$ where the superscripts $b m$ and $a m$ denote the threshold value $\alpha_{C R}$ before and after the merger. If $\phi$ is stricly greater than unity, then the border line $\alpha_{C R}$ in figure 1 moves down. Therefore, there exists some values of $\alpha$ and $p$ for which firms collude and reveal before merger whereas they do not collude if the merger is accepted by the AA. In other words, a merger would attenuate the scope of collusion.

To simplify calculations, we assume that $c=0$.

Individual profit functions of the firms $(\forall i=1 \ldots n)$ are given by :

$$
\left\{\begin{array}{l}
\pi_{M}=\frac{1}{6} k_{i} \\
\pi_{D}=\frac{k_{i}\left(-2-k_{i}\right)^{2}}{18\left(1+2 k_{i}\right)} \\
\pi_{N}=\frac{\beta_{i}\left(2 k_{i}-\beta_{i}\right)}{2 k_{i}(1+\beta)^{2}}
\end{array}\right.
$$

with $\beta_{i}=\frac{k_{i}}{k_{i}+1}$.

Proof. See Appendix A.

These profit functions correspond to the case where a proposed merger is rejected in the first period ( $n$ firms compete in the industry). If the merger is accepted in the first period ( $n-1$ firms), production capacity of the merger entity is calculated as follows : $k_{1+2}=k_{1}+k_{2}=2 k_{1}$.

Numerical simulations of $\phi$ and $\tilde{\delta}$ are represented in figure 2 in the appendix.

We see in figure 2 for $k_{1}$ high enough $\left(k_{1}>0.3\right)$ and where $\delta$ is sufficiently high that $\phi>1$. But for low values of $k_{1}, \phi$ is always stricly less than unity (which is normalized by a plane with $\phi=0$ ).

lemma 2. With high (resp. low) production capacity of the merging firms, a merger will cause the border line $\alpha_{C R}$ to move down (resp. up) 
As noted before, we do the same with the other border lines $\alpha_{N C}$ and $s_{C N R}$ and two lemmas follow :

lemma 3. With high (resp. low) production capacity of the merging firms, a merger will cause the border line $\alpha_{N C}$ to move to the southwest (resp. northwest)

lemma 4. With high (resp. low) production capacity of the merging firms, a merger will cause the border line $s_{C N R}$ to move to the left (resp. right).

All these lemmas are summarized in Figure 3 in the appendix.

The following proposition gives the impact of a merger on collusion :

proposition 1. The impact of a merger on collusion

- With high (resp. low) production capacity of the merging firms, a merger will reduce (resp. increase) the space of parameters under which firms tend to collude.

- With high (resp. low) production capacity of the merging firms, a merger will increase (resp. reduce) the space of parameters under which firms tend to collude with revelation, in comparison with the space of parameters under which firms tend to collude without revealation.

The inference to be drawn from this result is that the larger the firm, the more able it is to derogate from the collusion agreement because the ability of outsiders to punish deviations is attenuated.

\subsection{Profitability of the merger}

In this section we study the profitability incentives for a merger.

First, comparison must be between the individual profit of a merging firm and the individual profit of this firm without any merger in a Nash environment. 
To simplify we denote by $\pi_{i n d}^{N}(M)$ (resp. $\left.\pi_{i n d}^{N}(\oslash M)\right)$ the individual profit of a firm prior to merge in a Nash environment with the merger (resp. without the merger).

When we compute the static profits, we obtain :

$$
\pi_{\text {ind }}^{N}(M)>\pi_{\text {ind }}^{N}(\oslash M)
$$

So the actualised profits of the firms are greater with a merger than without a merger :

$$
\pi_{i n d}^{N}(M)\left[1+\delta+\delta^{2}+\ldots\right]>\pi_{i n d}^{N}(\oslash M)\left[1+\delta+\delta^{2}+\ldots\right]
$$

Therefore, firms have incentives to merge if we do not take into consideration the possibility for firms to collude.

What is interesting is to compare the values of the profits when we take into account collusion. More precisely, we compare the interesting case in which a merger is accepted and no collusion follows with the case in which the merger is rejected with collusion after. There are two possibilities : $C R$ equilibrium and $C N R$ equilibrium.

The static profit of the firm 1 or 2 when all firms collude in the industry and without any merger is :

$$
\pi_{i n d}^{\text {coll }}(\oslash M)=\frac{k_{1}}{6}<\pi_{i n d}^{\text {Nash }}(M)
$$

- if the equilibrium strategy is $C N R$ the actualised profit (without merger) in a one-shot game is :

$$
\alpha\left(\pi_{\text {ind }}^{\text {coll }}+\delta\left(\left[(1-s)\left(\pi_{\text {ind }}^{\text {coll }}\right)+s\left(\pi_{\text {ind }}^{N}(\oslash M)-F\right)\right]\right)\right)+(1-\alpha)(1+\delta) \pi_{\text {ind }}^{\text {coll }}
$$

- if the equilibrium strategy is $C R$ the actualised profit (without merger) in a one-shot game is :

$$
\left.(1-\alpha) \pi_{i n d}^{\text {coll }}+\alpha\left[\pi_{i n d}^{N}(\oslash M)-f\right)\right]
$$


The actualised profit in a Nash environment (with merger) is always greater than the actualised profit in $C R$ or $C N R$ environment because $\pi_{\text {ind }}^{N}(M)>\pi_{\text {ind }}^{N}(\oslash M)$ and $\pi_{\text {ind }}^{\text {coll }}(\oslash M)=\frac{k_{1}}{6}<\pi_{\text {ind }}^{\text {Nash }}(M)$. So the merger is always profitable.

\section{Conclusion and policy implications}

Assessing the scope for collusion is a difficult issue.

All the papers on mergers and collusion tend to look at a minimal discount factor threshold for collusion to be sustained. However, the fact that firms could sustain collusion does not mean that they really succeed in doing it. This paper does not only suggest necessary and sufficient conditions for collusion to be enforced but we do analyse the choice which firms have as to whether to collude. We look at the equilibrium path of firms; here we predict whether collusion is actually taking place.

We consider an industry with $n$ asymmetric firms. By asymmetry it is meant that firms have a different share of a specific asset that affects marginal costs (as suggested by Perry-Porter, 1985).

Some important policy implications can be derived from our results. They shed some light on the complex problem of assessing the potential jointdominance effects which some mergers bring about. The impact of a merger depends on the nature of the firms involved. The antitrust authorities have to approve, under certain conditions, a merger between two "big" firms in order to fight collusion (these result reinforce those obtained by Vasconcelos, 2005). But when small firms want to merge, the risk of collusion is increased.

Therefore, mergers reinforcing market asymmetry should be considered by AA as pro-competitive. Remark that this point is divergent from the analysis of unilateral effects because although the asymmetric distribution of costs has the effect of reducing the likelihood of collusion, the implication is, clearly, that dominance is increased. 


\section{Appendix A : Expression of profit functions}

\section{NASH PROFIT}

$\operatorname{Max}_{q_{i}}\left(a-b\left(\sum_{i=1}^{n} q_{i}\right)\right) q_{i}-\frac{q_{i}^{2}}{2 k_{i}}$

Then :

$Q=\frac{a \beta}{b(1+\beta)}$

$p=\frac{a}{1+B}$

$q_{i}=\frac{a}{b} \frac{\beta_{i}}{1+\beta}$

with $\beta_{i}=\frac{b k_{i}}{b k_{i}+1}$ and $\beta=\sum\left(\beta_{i}\right)$ (Cf McAfee and Williams, 1992).

\section{COLLUSION PROFIT}

As Vasconcelos (2005), we suppose that monopoly aggregate output is simply divided in proportion to capital endowments.

$$
\begin{aligned}
& \operatorname{Max}_{Q^{M}}\left(a-b Q^{M}\right) Q^{M}-\frac{\left(Q^{M}\right)^{2}}{2 \sum k_{i}}-c Q^{M} \\
& \sum k_{i}=1 \\
& Q^{M}=\frac{a-c}{2 b+1} \\
& q^{M}=k_{i} * \frac{a-c}{2 b+1} \text { and then we replace in the profit function to obtain the }
\end{aligned}
$$
collusion profit.

\section{DEVIATION PROFIT}

As in Rothschild (1999), we suppose here that deviation takes the form which is conventionally assumed in models of this type : the deviant takes the allocated cartel outputs of all other firms as given and selects the output which maximizes its own profits.

$$
\begin{aligned}
& \operatorname{Max}_{q_{i}}\left(1-b q_{i}-b\left(1-k_{i}\right)\left(\frac{a-c}{2 b+1}\right)\right) * q_{i}-\frac{q_{i}^{2}}{2 k_{i}}-c q_{i} \\
& q_{i}^{D}=\frac{1-c-b\left(1-k_{i}\right)\left(\frac{a-c}{2 b+1}\right)}{2 b+k_{i}^{-1}} \text { and then we replace in the profit function to }
\end{aligned}
$$
obtain the deviation profit. 


\section{References}

Abreu, D., 1986. Extremal equilibria of oligopolistic supergames. Journal of Economic Theory 39, 191-225.

Abreu, D., 1988. Towards a theory of discounted repeated games. Econometrica $56,383-396$.

Compte, O., Jenny, F., Rey, P., 2002. Capacity constraints, mergers and collusion. European Economic Review 46, 1-29.

Farrell, J., Shapiro, C., 1990. Horizontal mergers: an equilibrium analysis. American Economic Review, 80, 107-126.

Friedman, J.W., 1971. A non-cooperative equilibrium for supergames. Review of Economic Studies 28, 1-12.

McAfee, P., Williams, M., 1992. Horizontal mergers and antitrust policy. Journal of Industrial Economics 40, 181-187.

Motta, M., Polo, M., 2003. Leniency programs and cartel prosecution. International Journal of Industrial Organization 21, 347-379.

Perry, M., Porter, R., 1985. Oligopoly and the incentive for horizontal merger. American Economic Review 75, 219-227.

Rothschild, R., 1999. Cartel stability when costs are heterogeneous. International Journal of Industrial Organization 17, 717-734.

Salant, S., Switzer, S., Reynolds, R., 1983. Losses due to merger: the effects of an exogenous change in industry structure on Cournot-Nash equilibrium. Quarterly Journal of Economics 98, 185-199.

Vasconcelos, H., 2005. Tacit collusion, cost asymmetries, and mergers.The Rand Journal of Economics 36, 39-62. 


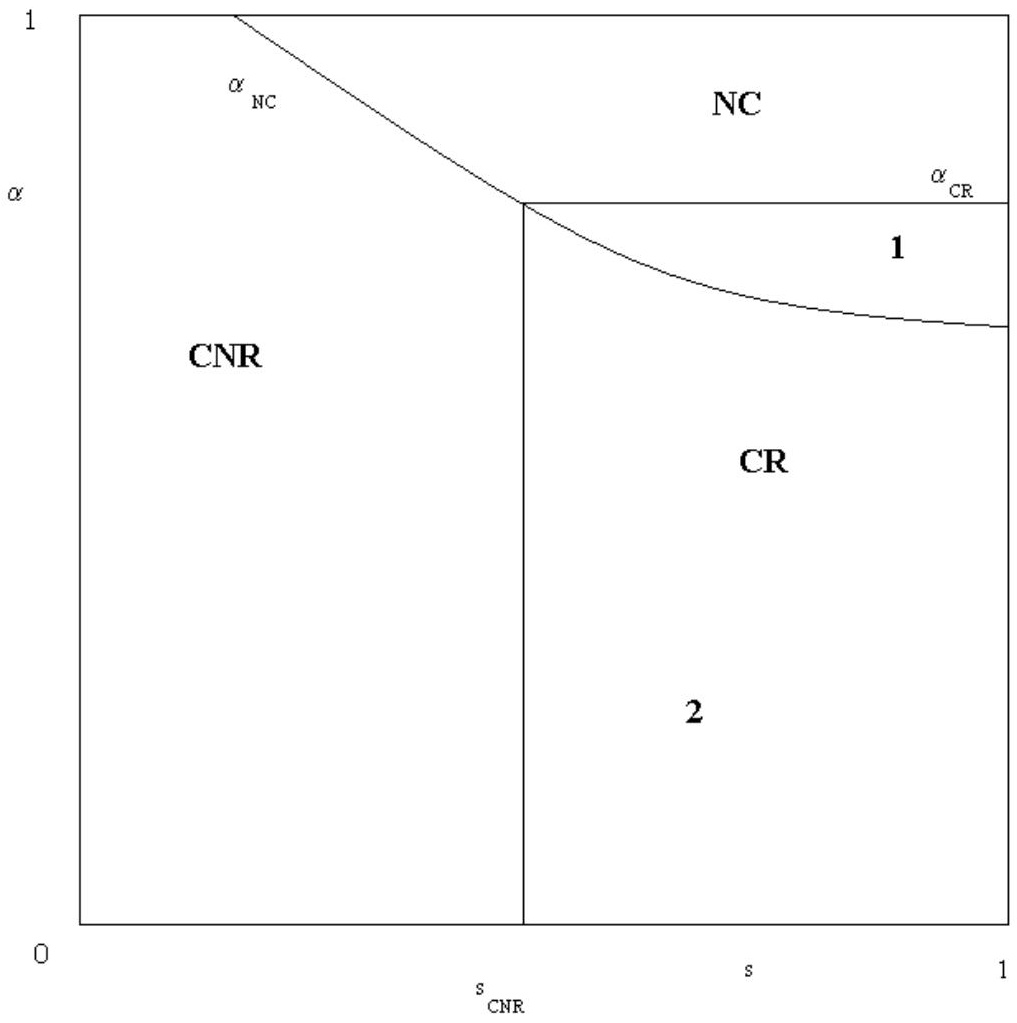

Figure 1: Subgame Perfect Equilibria 


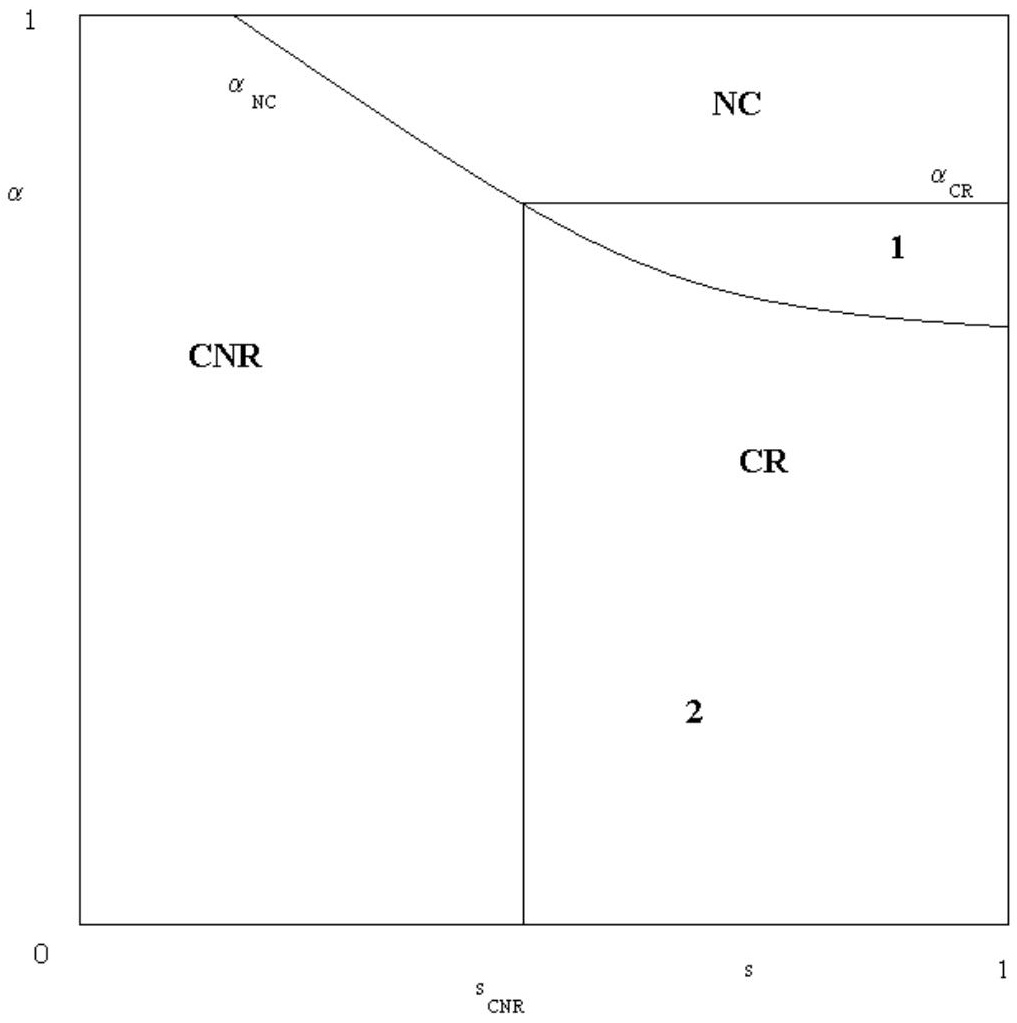

Figure 1: Subgame Perfect Equilibria 


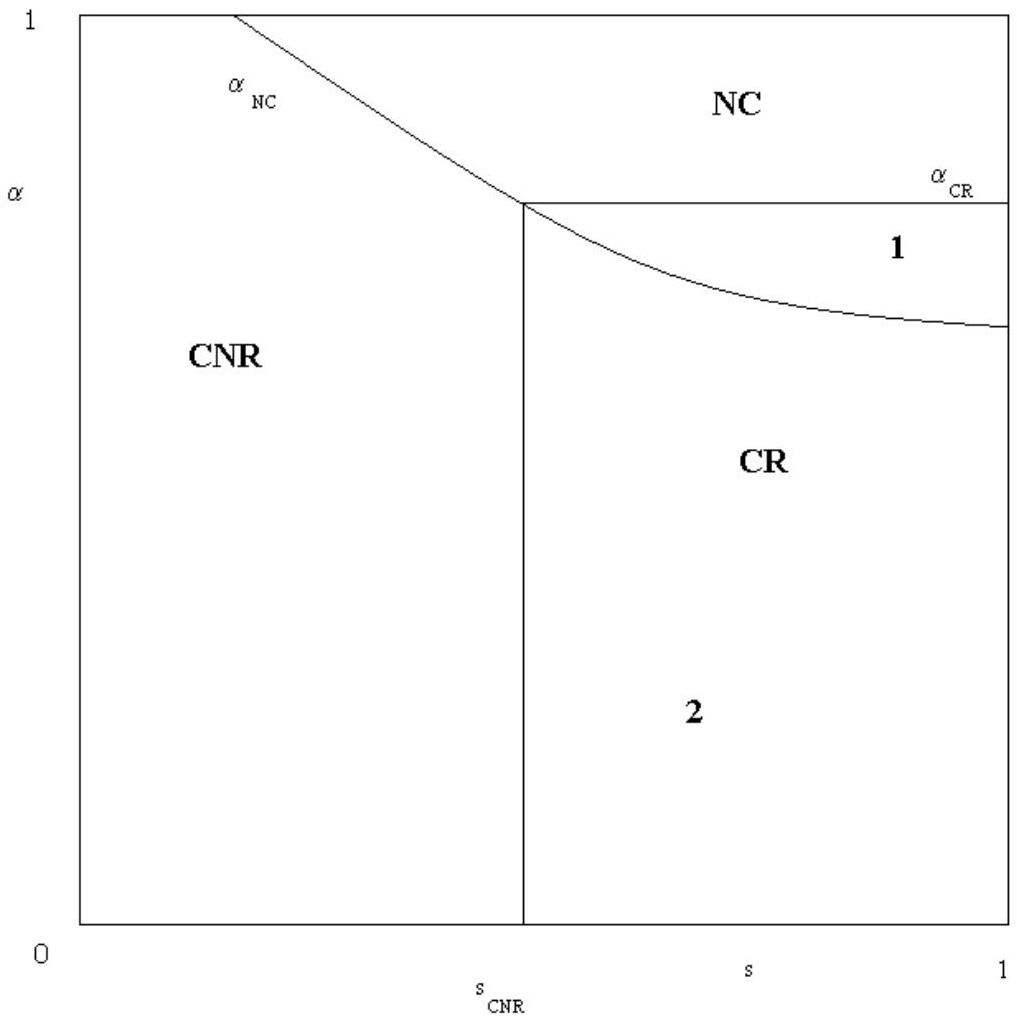

Figure 1: Subgame Perfect Equilibria 